\title{
Lightning-associated VLF perturbations observed at low latitude: Occurrence and scattering characteristics
}

\author{
Sushil Kumar and Abhikesh Kumar \\ School of Engineering and Physics, The University of the South Pacific, Suva, Fiji \\ (Received November 16, 2011; Revised May 19, 2012; Accepted May 30, 2012; Online published February 19, 2013)
}

\begin{abstract}
The occurrence of short-timescale $(\sim 1-100 \mathrm{~s})$ perturbations (early VLF events) on four Very Low Frequency (VLF) transmitter signals (call signs: NWC, NPM, VTX, NLK), recorded at Suva $\left(18.1^{\circ} \mathrm{S}, 178.5^{\circ} \mathrm{E}, L=1.16\right)$, shows the most frequent occurrence on the NWC signal and least on the VTX. Daytime early/fast events on the NWC transmission are $(0.2-0.5 \mathrm{~dB})$ with only negative amplitude perturbations with comparatively lower recovery times $(10-30 \mathrm{~s})$ as compared with most nighttime events with amplitude perturbations of $0.2-1.5 \mathrm{~dB}$ and recovery times of 20-80 s. The World-Wide Lightning Location Network detected causative lightnings for 74 of 453 early VLF events out of which $54(73 \%)$ were produced due to narrow-angle scattering, and by 20 (27\%) due to wide-angle scattering. The recovery (decay) of the scattered amplitude of early/fast events on the NWC signal shows both exponential and logarithmic forms, but the linear correlation coef cient is better with a logarithm t. The rst observations of early/slow events in daylight propagation are presented. Initial results on early/fast events with unusually long recoveries $(\geq 5 \mathrm{~min})$ and strong perturbations $(\geq 1 \mathrm{~dB})$ indicate that they are mainly observed on the transmissions from NPM and NLK in the nighttime only, with rare occurrence on other transmissions. Such unusually long recovery of early/fast events may be associated with large ionic conductivity perturbations associated with gigantic jets.
\end{abstract}

Key words: Early VLF perturbations, $D$-region ionosphere, transient luminous events, scattering.

\section{Introduction}

Very Low Frequency (VLF; $3-30 \mathrm{kHz}$ ) radio waves propagate through the atmospheric waveguide formed between the Earth's surface (ocean or ground) and the lowest region of the ionosphere ( $D$-region), which is called the EarthIonosphere Waveguide (EIWG). The VLF propagation from navigational transmitters undergoes short-timescale ( 1-100 s) perturbations called "early Trimpis" or "early VLF events", which are believed to be caused by direct lightning-induced effects in the $D$-region ionosphere. Armstrong (1983) rst reported the VLF perturbations that occurred within $100 \mathrm{~ms}$ (i.e., within the time resolution of the instrument) of the causative lightning discharges, which were thus termed "early" or "early/fast" events by Inan et al. (1988). Early VLF events are caused by scattering from the localized regions of the conductivity enhancements in the lower ionosphere associated with lightnings, producing Transient Luminous Events (TLEs) such as sprites, halos and elves (e.g., Dowden et al., 1994; Inan et al., 1996a; Sampath et al., 2000; Rodger, 2003; Haldoupis et al., 2004; Mika et al., 2005, 2006; Marshall et al., 2006; Kumar et al., 2008; Inan et al., 2010). However, from a comparison of early/fast VLF events with sprite observations in the USA on three dates (during 1995-2000) with high sprite activity, it was concluded that early/fast VLF

Copyright (C) The Society of Geomagnetism and Earth, Planetary and Space Sciences (SGEPSS); The Seismological Society of Japan; The Volcanological Society of Japan; The Geodetic Society of Japan; The Japanese Society for Planetary Sciences; TERRAPUB.

doi:10.5047/eps.2012.05.019 events and sprites were not well correlated as many sprites occurred even without any early/fast event and vice versa (Marshall et al., 2006). It has been shown that the electromagnetic pulses (EMPs) from successive in-cloud lightning discharges associated with cloud-to-ground discharges can produce appreciable $D$-region electron density perturbations which, in some cases, can produce weak early/fast VLF events (Marshall et al., 2008) even if there might not be any TLE associated with electron density perturbations. From the modeling results on the lower ionospheric modi cation by lightning EMPs, Rodger et al. (2001) have shown both electron density enhancement and reductions, depending upon the relative occurrence of weak or strong lightnings. From a study on the modeling of relaxation (recovery) times of early/fast VLF events, Haldoupis et al. (2009) found that most of the early VLF events are associated with electron density $\left(\mathrm{cm}^{-3}\right)$ enhancements of the order of $10^{2}-$ $10^{4}$ at altitudes of $75-85 \mathrm{~km}$. Recently, strong early/fast events due to large electron density enhancements in the $D$ region of the ionosphere associated with gigantic jets have been reported (van der Velde et al., 2010).

Inan et al. (1995) rst reported the connection between early/fast events and a small subset of sprites that occurred near the Transmitter-Receiver Great Circle Path (TRGCP), but at large distances from the receiver $(>2000 \mathrm{~km})$. They attributed these VLF perturbation events to narrow-angle forward scattering from enhanced ionization associated with lightning discharges located $\pm 50 \mathrm{~km}$ off the TRGCP and having a lateral extent of $\sim 100-150 \mathrm{~km}$. Dowden et al. (1996) observed early/fast events in a one-to-one rela- 
tionship with sprites located within $\sim 500 \mathrm{~km}$ around the receiver and attributed early/fast events to wide-angle scattering from sprite-generated columns of ionization with a shorter scale than the VLF wavelength. Early/fast events on the HWU and HWV transmitters, recorded at Crete station $\left(35.31^{\circ} \mathrm{N}, 25.08^{\circ} \mathrm{E}\right)$, were observed in a one-to-one association with sprites in conjunction with those positive cloudto-ground $(+\mathrm{CG})$ ashes that lead to the production of sprites (Haldoupis et al., 2004). Recently, from the analysis of optical and narrowband VLF data recorded simultaneously during Euro-Sprite campaigns 2003-2009, Haldoupis et al. (2010) have further concluded a one-to-one association between early VLF events and sprites. The concept of TLE-associated ionization changes producing narrowor wide-angle scattering of VLF transmissions has been under debate for many years. Some researchers have reported that a large fraction of early/fast events are associated with sprites due to wide-angle scattering (Dowden et al., 1996; Hardman et al., 1998) while others found that only a very small subset of sprites $(\sim 5 \%)$ showed characteristics of VLF backscatter (wide-angle scattering) from the sprite body (Mika et al., 2005; Marshall et al., 2006).

Early VLF events can be further classi ed into early/fast, early/slow, rapid onset rapid decay (RORDs), early steplike and unusually long recovery events. However, all types of early VLF events provide evidence of direct coupling between lightning and the lower ionosphere, observed to occur within $20 \mathrm{~ms}$ of a causative lightning discharge (Inan et al., 1988). Early/fast events are currently the most widelystudied subionospheric VLF perturbations, mainly at the mid-latitudes. A subset of early/fast events with larger onset durations termed "early/slow" events, were rst reported by Haldoupis et al. (2004). In contrast to early/fast events, early/slow events initially have a gradual growth in the observed VLF perturbations, and thus "slow" onset durations which range from about 0.5 to $2.5 \mathrm{~s}$ (Haldoupis et al., 2004, 2006).

Another subset of early/fast perturbations are step-like early/fast events mentioned by Sampath et al. (2000) and rst studied by Kumar et al. (2008) who reported that they mainly occurred for TRGCPs in the daytime. Unusually long recovery early/fast events were rst studied by Cotts and Inan (2007), but were mentioned in earlier publications (Inan et al., 1988, 1996a; Dowden et al., 1997) without any attention given to the unusual nature of the recovery times. Unusually long recovery events may, in practice, appear to be very similar to step-like events, due to the very slow recovery (Cotts and Inan, 2007).

In the current paper, we study the occurrence and scattering features of subionospheric early VLF events on transmissions from four VLF broadcast sites (call signs; NWC, NPM, VTX, and NLK) received at the low-latitude station Suva $\left(18.2^{\circ} \mathrm{S}, 178.3^{\circ} \mathrm{E}\right)$. We follow the convention of referring to the VLF transmitters by their call-signs. Observational results have been derived from VLF data recorded during the period November 2006-January 2007, a period of high lightning activity in the South Paci c Region. Earlier studies on this subject were limited to short campaigns and for nighttime periods only. This is the rst report of when both day and nighttime narrowband data have been continuously recorded and analysed for three months from four transmitters, and supplemented with lightning and broadband data. We report the rst evidence of early/slow events occurring when the TRGCPs were in daylight. We also present the initial observations from the Suva receiver station of early/fast events with an unusually long recovery of 5-20 min or more, and we discuss the possible mechanisms.

\section{Experimental Data}

A software-based VLF Phase and Amplitude Logger known as "SoftPAL" was used to record the amplitude and phase of VLF transmitter signals that are MSK (Minimum Shift Key) modulated (Dowden and Adams, 2008). MSK is a type of continuous-phase frequency-shift keying (modulation) which is encoded with bits alternating between quadrature $(Q)$ components, with the $Q$ component delayed by half the symbol period. The transmitter signals were recorded continuously with a time resolution of $0.1 \mathrm{~s}$ (i.e. sampling frequency of $10 \mathrm{~Hz}$ ), using GPS-based timing. We study early VLF events on NWC $\left(21.82^{\circ} \mathrm{S}, 114.17^{\circ} \mathrm{E}, 19.8\right.$ $\mathrm{kHz}, 1000 \mathrm{~kW}), \mathrm{NPM}\left(21.42^{\circ} \mathrm{N}, 158.15^{\circ} \mathrm{W}, 21.4 \mathrm{kHz}, 424\right.$ $\mathrm{kW})$, VTX $\left(8.39^{\circ} \mathrm{N}, 77.75^{\circ} \mathrm{E}, 18.2 \mathrm{kHz}\right.$, power not known), and NLK $\left(48.20^{\circ} \mathrm{N}, 121.92^{\circ} \mathrm{W}, 24.8 \mathrm{kHz}, 192 \mathrm{~kW}\right)$ transmitter signals received at Suva whose TRGCPs are shown in Fig. 1. The TRGCP distances are: 5.07 Mm for NPM, 6.69 Mm for NWC, $11.43 \mathrm{Mm}$ for VTX, and $9.43 \mathrm{Mm}$ for NLK to Suva. The TRGCPs for signals from NWC and VTX transmitters to Suva are over a mix of land and sea, whereas the TRGCPs for signals from NPM and NLK are purely over the sea. Our receiving station is at a low latitude $\left(18.2^{\circ} \mathrm{S}, 178.3^{\circ} \mathrm{E}\right)$ and the TRGCPs for NWC, VTX, and NPM are within a low-latitude belt, where classic VLF perturbation events associated with the whistler-induced precipitations (WEPs) into the lower ionosphere are very unlikely to occur. For these TRGCPs the entire paths have low magnetic L-shell values $(L<1.5)$ where WEPs have not been observed (Voss et al., 1998). However, a signal from the NLK transmitter, located at $L>1.5$, propagates from a mid-high latitude where WEPs can occur (Voss et al., 1998). Hence, the NLK signal may also have classic VLF events apart from early VLF events. Therefore, for the signal from the NLK transmitter, the observed VLF perturbations need to be combined with lightning-occurrence observations, or simultaneous perturbation events on signals from other transmitters (mainly NPM), to make sure that the observed perturbations are, in fact, early VLF events. Based on the signal-to-noise ratios of the received signals, a minimum detectable amplitude perturbation of $0.2 \mathrm{~dB}$ has been taken. Note, however, that weaker perturbations, of less than $0.1 \mathrm{~dB}$, can be observed on the signals received from the NWC and NPM transmitters.

To identify the causative lightnings of early VLF events, we analysed World-Wide Lightning Location Network (WWLLN) data (Dowden et al., 2008) for lightnings located within $500 \mathrm{~km}$ off the TRGCPs, and which occurred within $100 \mathrm{~ms}$ of the occurrence of early VLF events. In this study, we make use of WWLLN data processed by the Reloc-A algorithm (Rodger et al., 2006). In 2006, WWLLN Reloc-A data included 36.5 million lightning lo- 


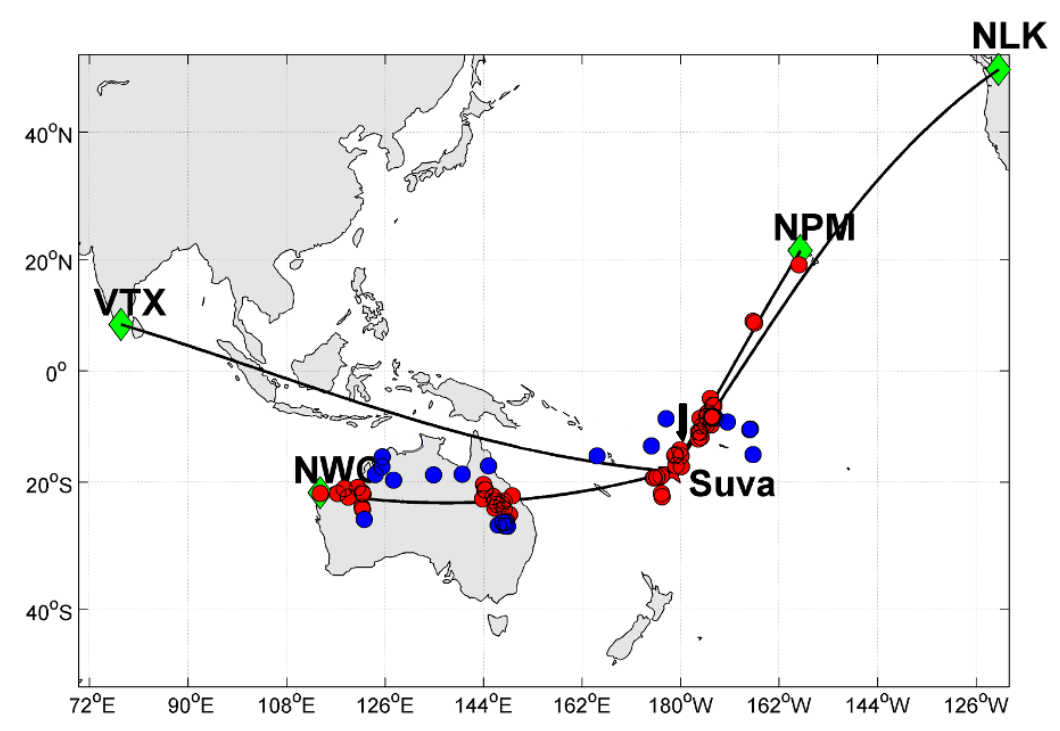

Fig. 1. Map showing the positions of the four VLF transmitters, receiving station, Suva, and their TRGCPs. Solid red and blue circles represent WWLLN-detected lightnings responsible for narrow- and wide-angle scatterings of early VLF events, respectively.

cations, which equates to a global lightning detection efficiency $\sim 2.6 \%$ (personal communication, Craig J. Rodger, 2011). With increasing WWLLN station numbers and improved processing algorithms, WWLLN global lightning rates have now increased by $\sim 4$ times, relative to the 2006 Reloc-A algorithm (personal communication, Craig J. Rodger, 2011). In addition, wideband VLF data recorded using the Suva WWLLN station for 5 minutes at every hour in the nighttime (18:00-06:00 LT, LT $=\mathrm{UT}+12 \mathrm{hrs})$ during the months of November and December 2006 have also been analysed to examine the sferics from possible causative lightnings at the time of occurrence of early/slow events (see Subsection 3.2).

\section{Results and Discussion}

3.1 Occurrence and scattering patterns of early VLF events

Early VLF events classified as early/fast, early/slow, RORDs, and early step-like events were all observed on the four transmitters monitored. The most common types were early/fast events. Early/fast events with an unusually long recovery were observed mainly on NPM and NLK seabased paths, and rarely on the signal from NWC and VTX transmitters. We discuss these unusual events in Subsection 3.3. Analysis of early/slow events is presented in Subsection 3.2, while RORDs have not been considered in the current study, and typical examples of step-like events have been reported by Kumar et al. (2008). For each day, all early VLF events (early/fast, early/slow, step-like, unusually long recovery events) were visually inspected for the period November 2006 to January 2007, and a count of perturbation events $(\geq 0.2 \mathrm{~dB})$ along with their time of occurrence and amplitude changes $(\Delta A)$ in $\mathrm{dB}$ was made. $\Delta A$ is the difference between the pre-event signal level and the signal level at the peak of perturbation. Overall, we found that 353 early VLF events occurred on NWC, 245 on NPM, 40 on NLK, and 17 on VTX signals associated with 453 lightning events. In the case of simultaneous early VLF events on two or more transmitter signals, the causative lightning has been counted as one lightning event. Clearly, early VLF events occur most frequently on the NWC signal and least on the VTX signal. The difference in the occurrence of early VLF events can be mainly attributed to the stability of signals, the occurrence of lighting discharges near the TRGCPs, the TRGCP distances, and the transmitter power and frequency. SoftPAL recording indicates that, at any time, NWC and NPM signals are highly stable, whereas VTX and NLK signals have a considerably larger signal variability. Due to the smaller signal-to-noise ratio, some of the weak early VLF events on VTX and NLK signals cannot be identified. The coupling among VLF modes over the long propagation paths may wash out the weaker early VLF events (Marshall et al., 2006) which are most likely to happen on the VTX and NLK signals due to longer TRGCPs. In addition, Christian et al. (2003) found that approximately $78 \%$ of lightnings on the Earth occur between $30^{\circ}$ around the geographic equator. Continental, island and coastal regions contribute $88 \%$ of the global total production. It is likely that the higher occurrence of early VLF events on the NWC signal is due to the higher lighting rate in the Australia region near the NWC-Suva TRGCP, and the high signal-to-noise ratio of transmissions from NWC.

Figures 2(a)-(d) present examples of typical early/fast events observed when TRGCPs were completely, or partly, in the dark. The date and time of occurrence of early/fast events are shown on the panels (a)-(d). The purpose of Fig. 2 is to demonstrate the SoftPAL data quality at Suva and to confirm that the early/fast events observed at Suva are similar to those reported by previous authors. It can be noted from this figure that early/fast events are particularly clear on the NWC signal, compared with those seen on other transmitter signals. The event on the VTX transmitter in panel 2(c) has an onset time of about $0.4 \mathrm{~s}$. The vertical dashed lines shown in each panel indicate the occurrence time of WWLLN-detected lightning discharges associated with these perturbations. In all these cases, WWLLN- 

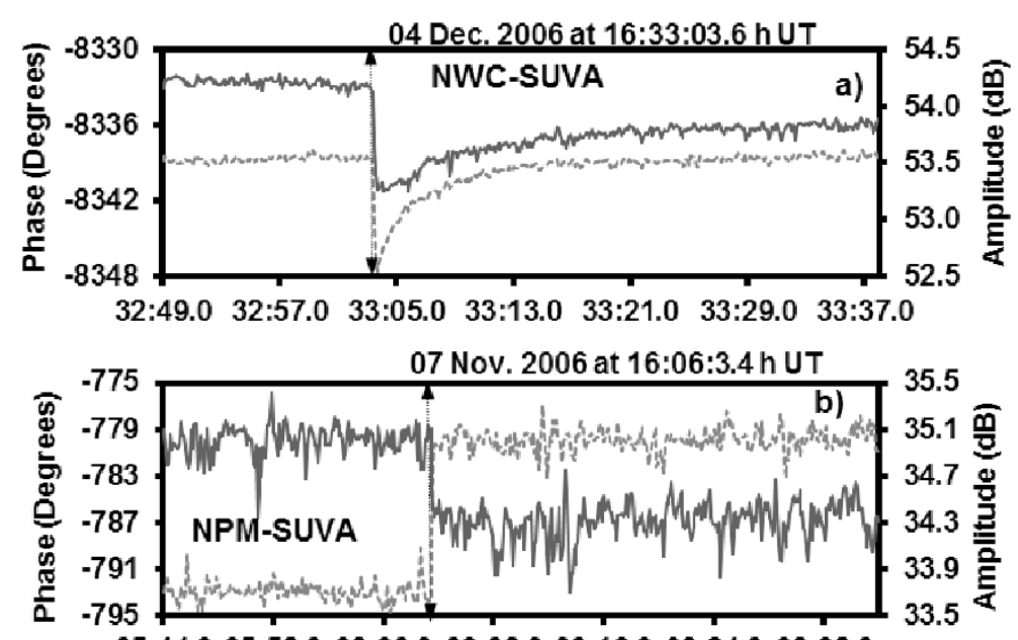

05:44.0 05:52.0 06:00.0 06:08.0 06:16.0 06:24.0 06:32.0
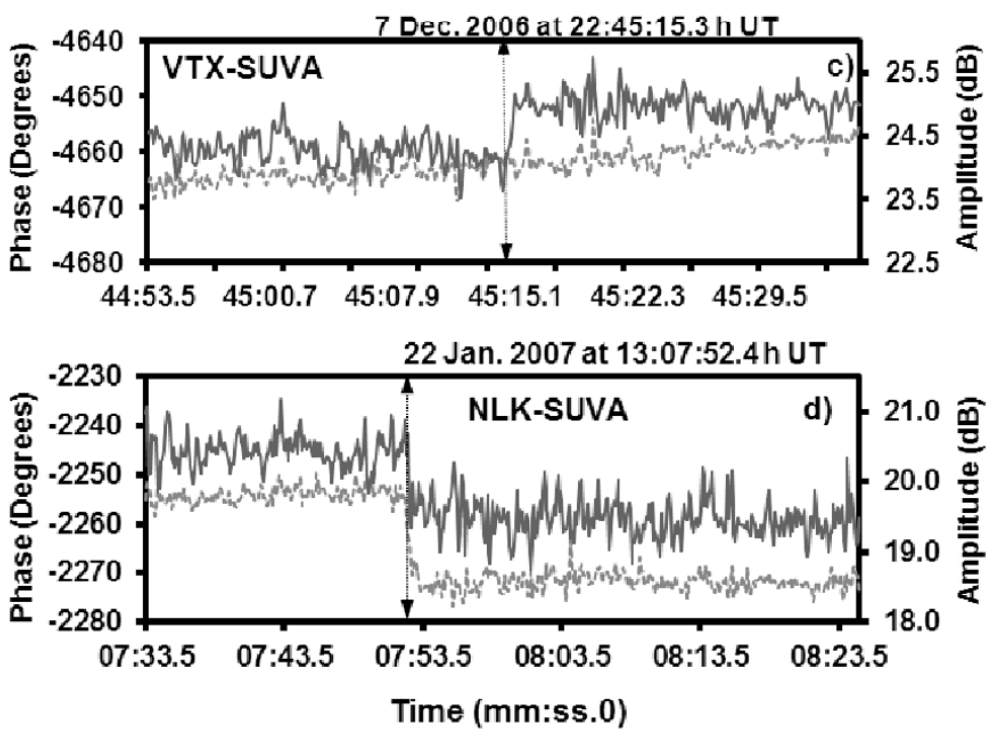

Fig. 2. (a)-(d) Typical examples of early/fast events observed on the NWC, NPM, VTX and NLK transmitters. Solid traces (blue color) and dotted traces (red color) represent the amplitude and phase, respectively. Dashed vertical lines indicate the time of WWLLN-detected lightnings.

Table 1. Parameters of early/fast VLF events on the NWC signal: change in amplitude $(\Delta A)$, change in phase $(\Delta \theta)$, nose duration of the events $\left(\tau_{n}\right)$, correlation coefficient of scattered amplitude for logarithmic fit $\left(r M_{\log }\right)$, correlation coefficient of scattered amplitude for an exponential fit $\left(r M_{\text {exp }}\right)$.

\begin{tabular}{|c|c|c|c|c|c|c|c|}
\hline No. & Date & Time (UT) (hh:mm:ss) & $\Delta A(\mathrm{~dB})$ & $\Delta \theta(\operatorname{deg})$ & $\tau_{n}(\mathrm{Amp})(\mathrm{sec})$ & $r M_{\log }$ & $r M_{\exp }$ \\
\hline 1 & $2 / 11 / 06$ & $15: 06: 15.2$ & 1.18 & -5.89 & 5.01 & 0.91 & 0.96 \\
\hline 2 & $2 / 11 / 06$ & $15: 43: 03.0$ & 1.24 & 2.68 & 12.34 & 0.76 & 0.44 \\
\hline 3 & $2 / 12 / 06$ & $12: 19: 50.0$ & -1.26 & 10.94 & 1.92 & 0.96 & 0.85 \\
\hline 4 & $2 / 12 / 06$ & $15: 09: 58.3$ & -1.52 & 11.40 & 4.98 & 0.99 & 0.89 \\
\hline 5 & $2 / 12 / 06$ & $16: 19: 58.3$ & -0.93 & -8.98 & 12.02 & 0.97 & 0.91 \\
\hline 6 & $04 / 12 / 06$ & $16: 33: 3.4$ & -0.95 & -8.25 & 17.98 & 0.95 & 0.86 \\
\hline 7 & $06 / 12 / 06$ & $12: 28: 33.7$ & -0.57 & 3.31 & 4.79 & 0.82 & 0.87 \\
\hline 8 & $06 / 12 / 06$ & $13: 48: 17.2$ & -0.64 & 3.25 & 6.70 & 0.93 & 0.87 \\
\hline 9 & $11 / 12 / 06$ & $12: 15: 18.9$ & 1.09 & -5.28 & 22.60 & 0.88 & 0.83 \\
\hline 10 & 06/01/07 & $17: 14: 20.7$ & -1.94 & 8.31 & 3.62 & 0.97 & 0.94 \\
\hline
\end{tabular}

reported lightning locations were within a sampling rate (100 ms) at which amplitude and phase data were recorded and within $50-100 \mathrm{~km}$ off the TRGCPs, indicating that these perturbation events were produced by narrow-angle scattering of the VLF signals from $D$-region conductivity changes associated with the lightning discharges. Given the 100-ms sampling interval and low detection of WWLLN, there could be other comparatively weak strokes at some distance away associated with the same lightning storm not detected by WWLLN. The scattering amplitude $(M)$ of the event on the NWC signal in Fig. 2(a) was modeled using the model suggested by Dowden and Rodger (1997), given 


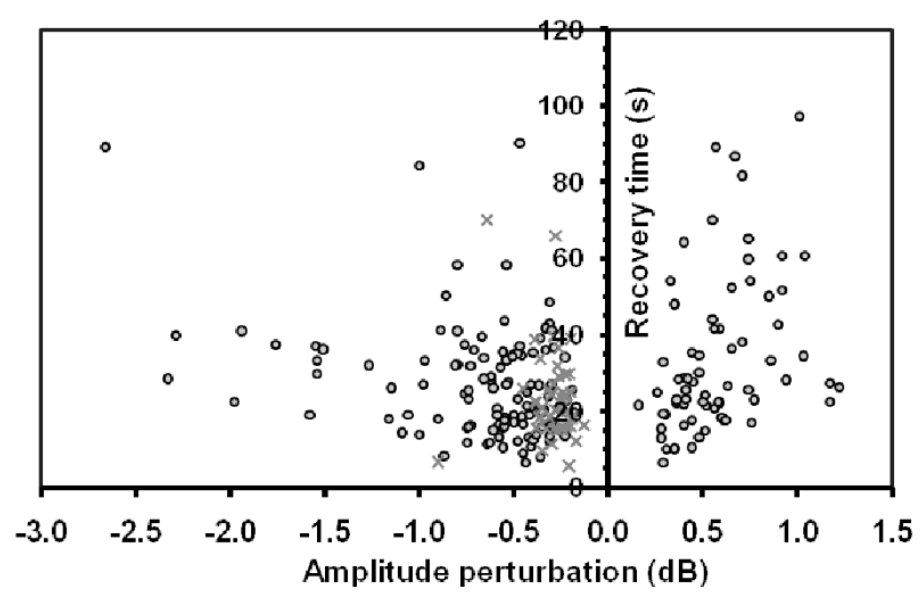

Fig. 3. The relationship between the perturbation in amplitude and recovery times to $95 \%$ of the decay of 168 early/fast events during nighttime (marked with circles), and 45 early/fast events during daytime (marked with crosses), observed on transmission from NWC.

by $M=\sqrt{R^{2}+1-2 R \cos \Delta \theta}$, where $R\left(A / A_{0}\right)$ is the ratio of the amplitude of the perturbed wave $(A)$ to the unperturbed wave $\left(A_{0}\right)$ in $\mathrm{dB}$ and $\Delta \theta\left(\Delta \theta=\theta-\theta_{0}\right)$ is the phase of the perturbed wave $(\theta)$ minus the phase of the unperturbed wave $\left(\theta_{0}\right)$ in degrees. The recovery times of the scattered amplitude were fitted into logarithmic and exponential forms. The correlation coefficient $(r)$ of the logarithmic fit $(r=0.95)$ is higher than the exponential fit $(r=0.86)$. The amplitude perturbation $(\Delta A)$ in $\mathrm{dB}$, phase perturbations $(\Delta \theta)$ in degrees, duration of nose $\left(\tau_{n}\right)$ in second, and the values of the linear correlation coefficient $(r)$ of $M$ for the logarithmic and exponential fit curves for 10 early/fast events, are given in Table 1. $\tau_{n}$ is determined as the time taken for the amplitude to recover to $50 \%$ of the initial maximum perturbation level. The duration of $\tau_{n}$ for amplitude perturbations for most events varied from about 2-17 s, with a maximum of about $23 \mathrm{~s}$. Molchanov et al. (1998) suggested two different regimes in the temporal behavior of most of the Trimpi events; an initial "nose" of about 1-5 s and a later "tail" of about 50-100 s. It can be seen from Table 1 that the $r$ values for the logarithmic fit curves are better when compared with the exponential fit curves, confirming the decay form of the scattered amplitude of early/fast events to be closer to the logarithmic variation (Dowden and Rodger, 1997), suggesting that these events were associated with sprite-like ionization enhancements. Molchanov et al. (1998) discovered an exponentialhyperbolic fit for weak scattering and a logarithmic fit for strong scattering. Early/fast events on other signals cannot be modeled in the same way, due to larger signal fluctuations (i.e., higher noise levels).

Early/fast events can be classified on the basis of their recovery times as short $(\sim 30 \mathrm{~s})$, medium $(\sim 100 \mathrm{~s})$ and long ( $\sim 250 \mathrm{~s}$ ) events (Haldoupis et al., 2009). In our data, early/fast events on transmissions from NWC are most clear (e.g. Fig. 2(a)) and also show the most well-defined recovery form when compared with those observed on other transmitter signals. Therefore, early/fast events observed on transmissions from NWC were examined for the relationship between the amplitude change $(\Delta A)$ and the recovery times of $95 \%$ of the decay taking $5 \%$ lower ionospheric variability over the recovery times. This analysis was undertaken using early/fast events when the entire NWC-Suva TRGCP was in the nighttime (23:00-06:00 LT) and in the daylight (06:00-22:00 LT) during November 2006-January 2007. The results are shown in Fig. 3. Looking at this figure, it can be said that for early/fast events with negative amplitude perturbations $>-1.0 \mathrm{~dB}$, the recovery time varies with the level of perturbations; however, the correlation coefficient of the linear fit for all the events is poor $(r \leq 0.3)$ indicating a random distribution of the amplitude perturbations versus the recovery times. Early VLF events with an unusually long recovery (given in Subsection 3.3) are very rare and have not been included in Fig. 3. The majority of nighttime early/fast events on the NWC signal are short recovery $(63 \%$, i.e. 118 out of 186$)$ while others have medium recovery times. It can be noted from Fig. 3 that about $66 \%$ (122 out of 186) of nighttime early/fast events have negative amplitude perturbations, and that large perturbation $(\geq 1.5 \mathrm{~dB})$ events are only negative amplitude perturbations. The daytime early/fast events (marked with crosses) are weak $(0.2-0.5 \mathrm{~dB})$ with only negative amplitude perturbations and, in general, have comparatively lower recovery times $(10-40 \mathrm{~s})$ as compared with nighttime perturbation events (10-60 s). Early/fast events observed in the nighttime, particularly with amplitude perturbations $>1.0 \mathrm{~dB}$, have longer recovery times. Previous studies have shown that waveguide mode interference arising through the independent scattering and absorption of the various VLF modes, off the conductivity disturbance and absorption of each mode, can lead to both negative and positive changes in amplitude (Marshall et al., 2008). The week (0.2-0.5 $\mathrm{dB}$ ) daytime amplitude perturbations are due to the higher attenuation offered by the Earth-ionosphere waveguide to VLF waves in the daytime as compared with the nighttime (Kumar et al., 2007) so that the waveguide mode interference between the scattered modes and the direct wave at the receiver results in a weaker amplitude in the daytime. The received amplitude and its polarity are strongly dependent on a number of parameters; in particular, the path length, the position of the disturbance relative to the receiver, ionospheric ground parameters, and the transmitter 
frequency (Marshall and Inan, 2010). Based on the results from the VLF scattering from red sprites, Rodger and Nunn (1999) have shown that the internal electrical structure in a sprite could lead to four combinations of amplitude and phase perturbations $(A \theta=++,--,-+,+-)$ of early VLF events, where + in amplitude means an increase, in amplitude means a decrease, + in phase means advance and - in phase means retard. The large negative perturbations ( $\geq 1.5 \mathrm{~dB}$, Fig. 3) which occur rarely seem to be associated with strong CG lighting strokes creating substantial electron density enhancements, and, or due to, destructive modal interference between the direct and scattered signals even from smaller electron density perturbations (Marshall and Inan, 2010). Early VLF perturbations associated with TLEs were modeled using the Gloukhov-Pasko-Inan (GPI) chemical model to represent the relaxation of transient ionization in the $D$-region ionosphere (Haldoupis et al., 2009). They have concluded that early VLF perturbations are associated with electron density $\left(\mathrm{cm}^{-3}\right)$ perturbations of the order of $10^{2}-10^{4}$ in the altitude range of $70-85 \mathrm{~km}$. When we apply modeling results of Haldoupis et al. (2009) to our results in Fig. 3, it can be estimated that the majority of early/fast events with recovery times of 10-40 s on the NWC signal are associated with an electron density perturbation of the order of $10^{3}-10^{4}$, in the altitude range of $75-$ $85 \mathrm{~km}$. While a shorter recovery $(<10 \mathrm{~s})$ is associated with an electron density perturbations at a slightly lower altitude $(70 \mathrm{~km})$, the events with medium recovery times $(>40 \mathrm{~s})$ are associated with electron density perturbation of the order of $10^{2}$ in the altitude range of $75-80 \mathrm{~km}$. The daytime events are associated with stronger electron density perturbations at lower altitudes, where recovery times are faster due to higher collision frequencies. Electron collisions play an important role in the recovery of VLF perturbations and also the attenuation of VLF waves propagating through the $D$-region.

The occurrence of early VLF events in the daytime is much lower than in the nighttime, as expected from the lower reflection height due to the larger $D$-region electron density during the day and the requirement of lightnings with a larger charge moment change to produce ionization at the lower altitudes. Out of 154 early VLF events observed when the TRGCPs were completely in the daylight, 74 were step-like, 70 were early/fast, and 10 were early/slow events. All the daytime early step-like, and early/fast, events were observed as perturbations in the received amplitude with no detectable phase signatures. Figure 4(a) and (b) shows a particular example of daytime early/fast events observed simultaneously on the NWC, NPM, VTX, and NLK signals at 21:46:55.8 UT (or 09:46:55.8 LT) on 5 November 2006, with the onset of the early/fast event marked as " 2 ". The amplitude change of this early fast event on the NWC, NPM, NLK and VTX signals are $0.80 \mathrm{~dB}, 0.97 \mathrm{~dB}$, $0.97 \mathrm{~dB}$, and $1.40 \mathrm{~dB}$, respectively. Such events have rarely been observed. The decrease in amplitude marked with " 1 " (appearing as RORD) could be due to sferics burst intrusion. The recovery of the early/fast event marked as 2 is faster $(\sim 10 \mathrm{~s})$ than the recovery times of most of the nighttime early/fast events observed at Suva station. Early/fast events seen in Fig. 4 on NWC and NPM (Fig. 4(a)) sig-

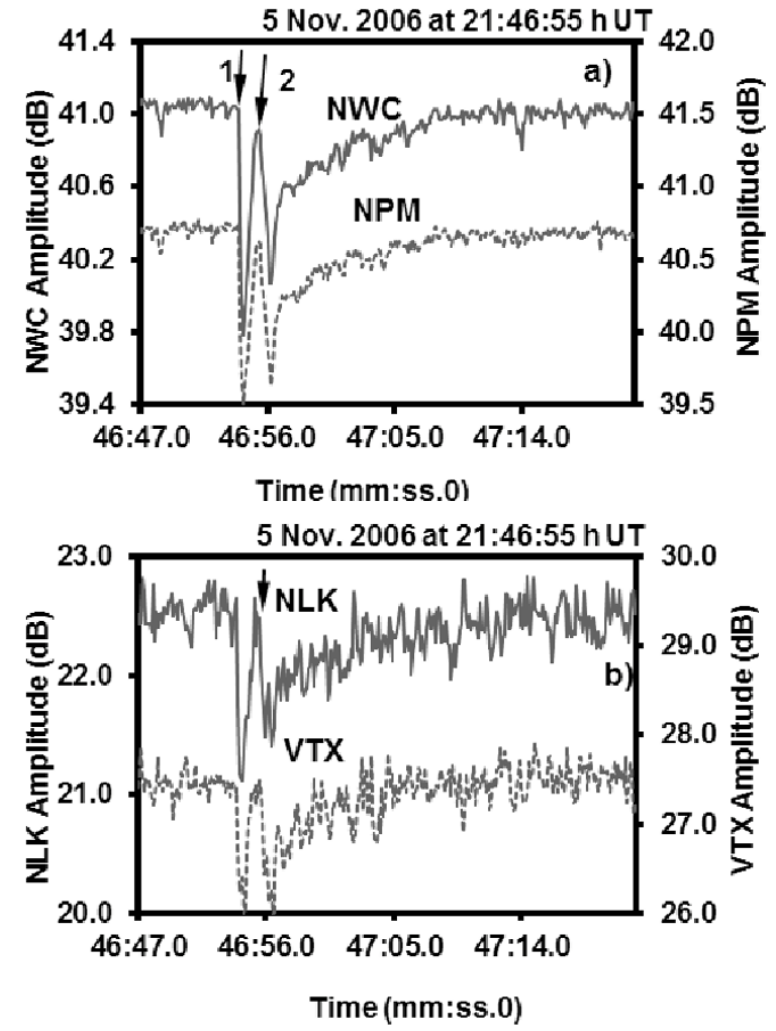

Fig. 4. (a)-(b): Daytime early/fast events observed simultaneously on NWC, NPM, NLK, and VTX signals on 5 November 2006 at 21:46 UT. All transmitter signals show the early/fast perturbation preceded by a RORD.

nals are clearer than those on VTX and NLK (Fig. 4(b)) signals. The simultaneous occurrence and same recovery times on all transmitter levels, but with different changes in amplitude, indicates that these early/fast events were produced by localized ionization due to strong lightning with a large charge moment change located overhead, or very near the receiver. Although the lightning activity is higher over the continents, intense lightnings (large charge moment change) occur more over the ocean than over the continent (Füllekrug et al., 2002). Most of the section of TRGCPs to Suva lies over the ocean thus giving a greater probability of occurrence of daytime early VLF events at our station than over the continents. However, in this case, WWLLN did not detect any lightning that was coincident with these perturbations, primarily due to the low detection efficiency of WWLLN, particularly in the daytime, due to the larger attenuation offered by the daytime EIWG for the ELF-VLF sferics propagation. The occurrence of daytime early/fast events (Figs. 3 and 4) indicates the strong possibility of the occurrence of daytime TLEs, or electron density perturbations, associated with strong lightnings. However, shorter recovery times of daytime early VLF events indicate that these events are generated by electron density perturbations at lower altitudes, where relaxation times are faster, associated with the daytime sprites occurring at lower altitudes $(\sim 50 \mathrm{~km})$ compared with most of the nighttime sprites which occur at higher altitudes, or with the strong EMPs, associated with strong lightnings. Chen et 
al. (2008), based on the Imager of Sprites and Atmospheric Lightnings (ISUAL) onboard FORMOSAT2 observations, have reported that the relative frequency of high peak current lightning ( $>80 \mathrm{kA})$ is 10 times higher over the oceans than over the land. This suggests the more likely occurrence of daytime early VLF events on the sea-based paths compared with land-based paths as reported in this study. Haldoupis et al. (2009), from a modeling study on the relaxation of early VLF events associated with TLEs, have shown that events with shorter recoveries are likely to come from lower altitudes compared with events with longer recoveries. Also it has been estimated that an unusually large charge moment change of about $8000 \mathrm{C}-\mathrm{km}$ is required to initiate a daytime sprite at a $50-\mathrm{km}$ altitude (Fernsler and Rowland, 1996). Stanley et al. (2000) detected 3 separate daytime sprites on 14 August, 1998, via a unique sprite ELF signature recorded at a site in New Mexico, following exceptionally large lightning discharges. Farges et al. (2005) were the rst to measure infrasound waves emitted from sprites past sunrise and onwards into the daytime, and suggested the occurrence of daytime sprites. Given that the signatures of daytime sprites (ELF and infrasound) have been detected by researchers, there is a possibility that daytime early VLF events reported here were associated with daytime sprites.

Early VLF events due to lightning discharges located $\pm 50-100 \mathrm{~km}$ off the TRGCPs have been attributed to narrow-angle forward scattering (Inan et al., 1995), whereas those due to lightning discharges located $\pm 100-500 \mathrm{~km}$ off the TRGCP (or even behind the receiver) have been attributed to wide-angle scattering (Dowden et al., 1996). The lightning discharges located $\pm 50-100 \mathrm{~km}$ around the receiver and/or transmitter have also been attributed to narrow-angle forward scattering, as the area with perturbed electron density due to lightning discharges would overlap the transmitter or receiver. To identify the causative lightnings for all early VLF events (early/fast, early/slow, steplike early and unusually long recovery events) and hence the nature of the associated scattering, we analysed WWLLN lightning data for locations within $500 \mathrm{~km}$ off the TRGCPs, coincident with the perturbations. WWLLN data provides the time and location of the global lightnings with return stroke currents of more than $\sim 50 \mathrm{kA}$, with a spatial and temporal accuracy of roughly $10-20 \mathrm{~km}$ and $10 \mu \mathrm{s}$, respectively (Rodger et al., 2006). WWLLN detected causative lightnings for 74 of our early VLF events. Under the above criteria, we found that about $73 \%$ (54 out of 74) events were associated with narrow-angle scattering and about $27 \%$ (20 out of 74) with wide-angle scattering. The locations of lightnings producing early VLF events by narrow-angle, and by wide-angle, scatterings, with respect to TRGCPs are indicated by solid red and blue circles in Fig. 1, respectively. In addition, there were 5 WWLLN detected lightnings which were located more than $600-800 \mathrm{~km}$ from the respective TRGCPs. These were coincident with Suvaobserved early VLF events. However, these events have not been included in our study as they fall outside the literaturebased criteria we have used to de ne narrow-angle, and wide-angle, scatterings. It is possible that these events may be extreme examples of wide-angle scattering.
The physical nature and conductivity pro le of ionospheric disturbances involved in early VLF events and the occurrence of these events with narrow-angle, and wideangle, scattering is still under dispute (Dowden, 1996; Dowden et al., 1996; Inan et al., 1996b; Dowden and Rodger, 1997; Hardman et al., 1998; Marshall et al., 2006) and requires more experimental data from different regions. From the simultaneous observations of early/fast events at nine closely-spaced $(\sim 65 \mathrm{~km})$ stations in the USA, and using a numerical model of the wave propagation and scattering of VLF signals in the Earth-ionosphere waveguide, Johnson et al. (1999) concluded that the ionospheric disturbance exhibits narrow forward VLF scattering patterns with $15 \mathrm{~dB}$ beam widths of less than $15^{\circ}$, consistent with their horizontal extent of $90 \pm 30 \mathrm{~km}$. Mika et al. (2005) reported about $5 \%$ of backscatter (wide-angle scattering) from the sprite body, in part supporting the earlier observations reported by Dowden et al. (1996), who concluded backscattering was possible. However, Dowden et al. (1996) and the subsequent papers from that group concluded that wideangle scattering of VLF waves from TLE-produced plasma was very common. From early/fast events and sprite observations in the USA, Marshall et al. (2006) reported that only a very small subset (9 out 250) of sprites shows characteristics of the VLF wide-angle scattering from the sprite body, and that all such cases correspond to multiple sprites or horizontally expansive sprites. Early/fast events associated with wide-angle scatterings have been reported under the EuroSprite-2007 (NaitAmor et al., 2007). The narrowangle scattering of VLF signals has also been reported to be associated from smoother and larger regions of the enhanced electron density (Dowden et al., 1996) and wideangle scattering associated with columns of enhanced ionization due to strong sprites (Dowden and Rodger, 1997). More experimental work is required to better understand the link between the location of the TLE and the way narrowangle, and wide-angle, VLF scattering can lead to associated early VLF events. In the current study, we have analysed early VLF events associated with narrow-angle, or wide-angle scatterings on a statistical basis. WWLLNdetected lightning locations within $100 \mathrm{~km}$ off the TRGCP show that about $73 \%$ (54 out of 74) were associated with narrow-angle scattering. In contrast, about $27 \%$ (20 out of 74) were produced by wide-angle scattering from conductivity perturbations associated with WWLLN-detected causative lightning discharges located within 100-500 km off the TRGCPs. About $20 \%$ of early VLF events, both on NWC and NPM transmitters, occurred simultaneously, and in the period 00-24 UT on 30 January 2007, 38 early/fast events (not shown here) were observed at Suva on two, or more than two, VLF signals simultaneously. While the electron density disturbances largely lead to scattering in the forward direction, the simultaneous occurrence of early/fast VLF events supports the possibility of early/fast events at Suva due to wide-angle scattering. This indicates that in some instances, wide-angle scattering of VLF signals on one or more transmitters can cause the occurrence of many events over a long period. Our observations of early/fast events on 30 January 2007 are similar to those presented by Dowden et al. (1996) from their observations of early/fast 

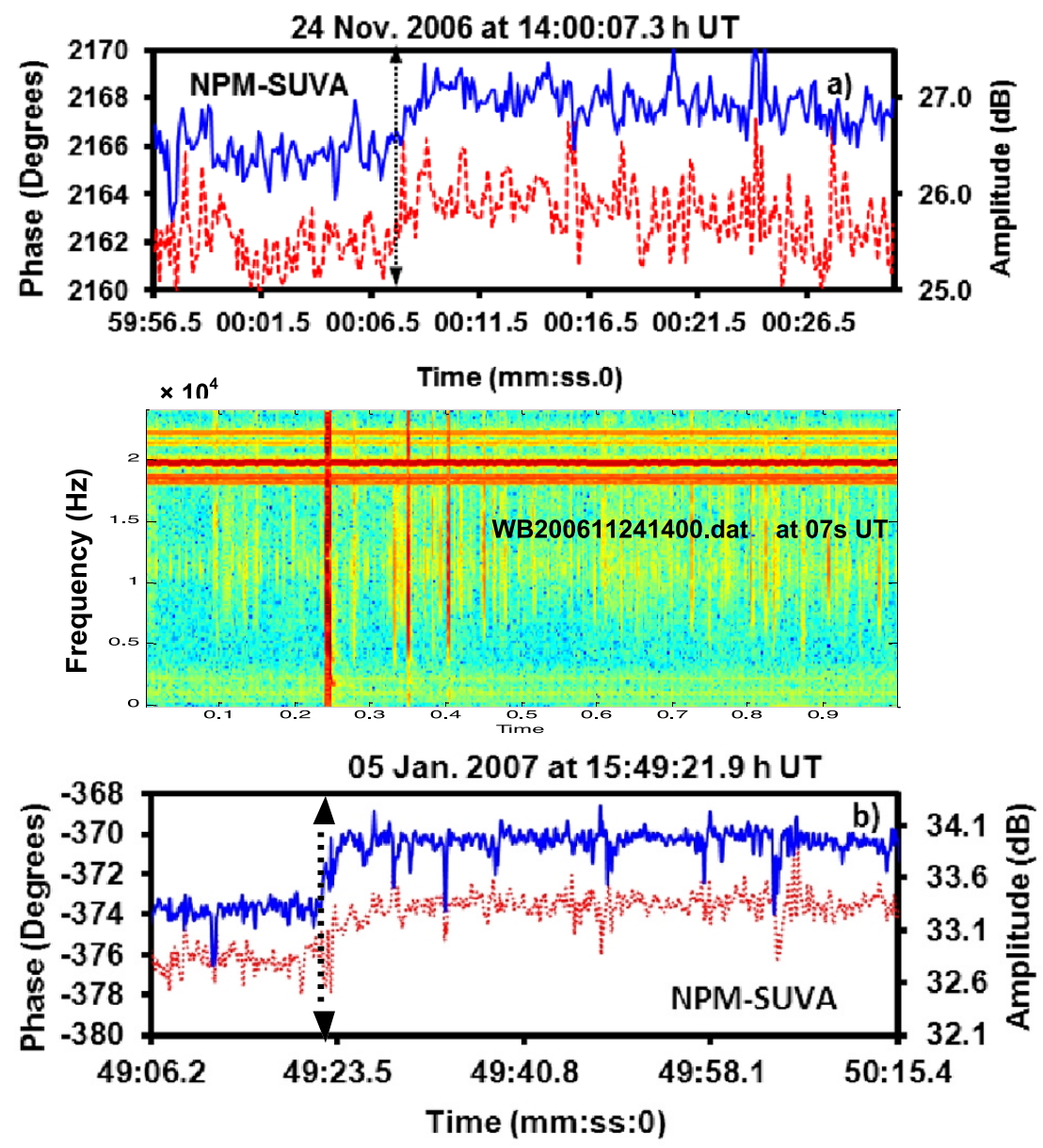

Fig. 5. (a)-(b): Early/slow events observed on NPM signal. Solid traces (blue color) and dotted traces (red color) represent amplitude and the phase, respectively. The spectrogram in middle gives the tweek sferics associated with causative lightning for event (a). The vertical dashed line in panel b) indicates the time of lightnings detected by WWLLN.

events on NAA, NSS, and NLK signals recorded at Boulder, USA. Also during EuroSprite-2008, on the HWU-Algiers TRGCP that passed within $\sim 350 \mathrm{~km}$ from the storm center, 28 of the 35 sprites $(80 \%)$ were associated with early VLF perturbations that displayed wide-angle scattering to an angle of about $70^{\circ}$ (Haldoupis et al., 2010), whereas the other paths displayed narrow-angle scattering.

\subsection{Early/slow events and sferic activity}

Previous data analysis has shown that in contrast to early/fast events, there is a sizable group of early VLF events that do not display a 'fast' onset; instead they have slow onset durations ranging from about 0.5 to $2.5 \mathrm{~s}$ and have thus been termed "early/slow" events (Haldoupis et al., 2004). In the period November 2006 to January 2007, a total of 47 early/slow events were observed, out of which 37 occurred when TRGCPs were completely in the dark. Figures 5(a) and (b) show examples of nighttime early/slow events on NPM when its TRGCP was in the dark. The date and time of occurrence of each early/slow event is given on the top of each panel. Early/slow events shown in panels (a) and (b) had onset durations of about 1.8-2.0 s both in the amplitude and phase. The accompanying wideband data shows the occurrence of sferics associated with the event in the panel (a). A very strong sferic with little dispersion (called a tweek) was observed at the occur- rence time of this early/slow event as marked by the arrow which has clear ELF components. The simultaneous occurrence of a strong tweek sferic having ELF $(<1.8 \mathrm{kHz})$ frequency components suggests that this sferic may be produced by causative strong lightning or by TLEs, probably red sprite associated with strong lightning. However, it is not possible to identify whether the ELF part is associated with currents flowing within the body of sprites or with the causative lightning discharge. Pasko et al. (1998) have reported that the causative lightning and sprite radiate almost simultaneously in time and the electromagnetic radiation in the ELF range produced by sprites could be comparable to that radiated by the causative lightning discharge. This tweek sferic was followed by two other weaker sferics with some ELF components and few more sferics without ELF components (VLF sferics). The enhanced VLF activity is indicative of Intra-Cloud (IC) lighting in association with sprites (Ohkubo et al., 2005). This indicates that strong CG lightning initiated this early/slow event and the weak CGs and IC lightnings, or in-cloud horizontal component of CG discharges, contributed to its slow onset which produce primary and secondary ionizations, respectively (Haldoupis et al., 2006). The long onset duration of early/slow events may be due to secondary ionization build-up in the upper $D$-region below the night-time VLF reflection heights pro- 

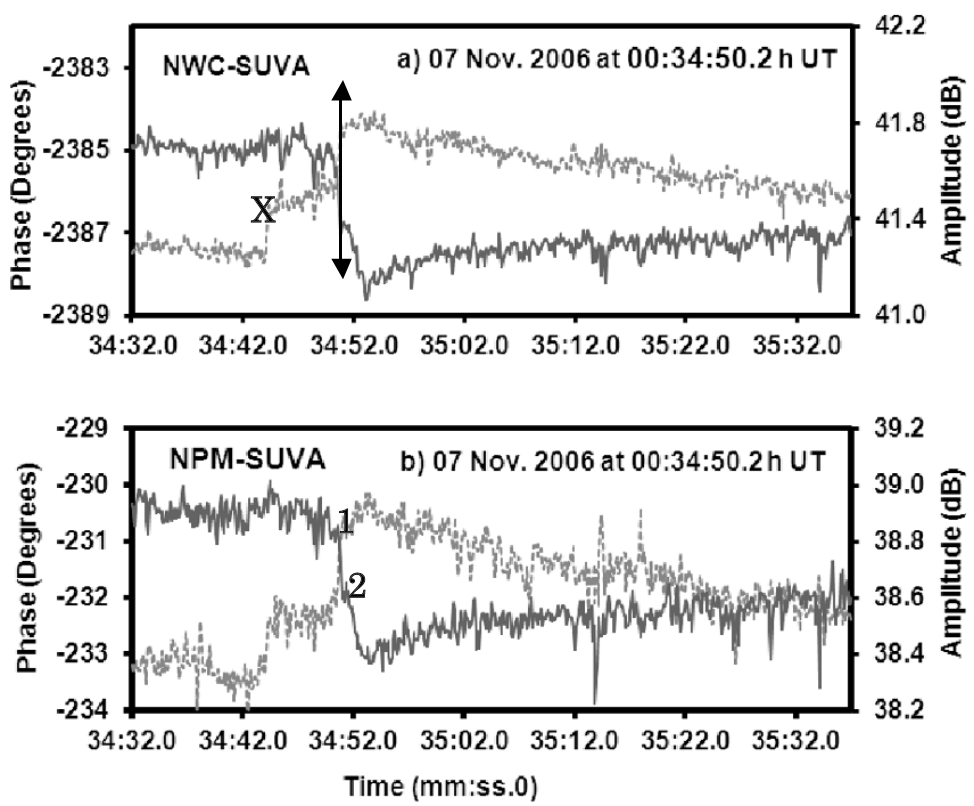

Fig. 6. (a)-(b): Early/slow events observed simultaneously on transmissions from NWC and NPM which occurred in the daytime at 00:34:50.2 UT (12:34:50.2 LT). Solid traces (blue color) and dotted traces (red color) represent amplitude and the phase, respectively. The solid line with arrows in panel (a) shows time of occurrence of VLF perturbation event.

duced by a quasi-electric field (QE) of sferics with ELF components and EMP fields of successive horizontal IC discharges, or an in-cloud horizontal component of CG discharges. The distance travelled by the tweek sferic in the EIWG (assumed perfectly conducting) calculated using the method used by Kumar et al. (1994) is found to be 1100 $\mathrm{km}$, within an accuracy of $600 \mathrm{~km}$, indicating that the lightning discharge associated with this tweek occurred towards the receiver along the NPM-Suva (TRGCP) range of 5070 $\mathrm{km}$. For the early/slow event in panel (b), WWLLN detected a lightning discharge located at geog. lat. $15.3765^{\circ} \mathrm{S}$, and geog. long. $179.8999^{\circ} \mathrm{W}$. The location of this lightning was within $100 \mathrm{~km}$ off the NPM and NLK-Suva TRGCPs (indicated by an arrow in Fig. 1) which shows that this particular event was produced by narrow-angle scattering. The slow onset of early VLF events implies an underlying mechanism which causes a gradual build-up of ionization following a causative $\mathrm{CG}$ discharge. Some researchers (Haldoupis et al., 2004, 2006; Mika et al., 2005; Kumar et al., 2008; Mika and Haldoupis, 2008) studied nighttime early/slow events and showed that the gradual onset of such perturbations is linked to complex and dynamic lightning activity, composed of a few CG return strokes and clusters of IC discharges, which produce primary and secondary ionizations, respectively. The secondary ionization is likely to be responsible for a gradual build up of ionization and hence the slow onset. ELF/VLF observational evidence suggests that strong IC activity may be associated with sprites (Ohkubo et al., 2005). The WWLLN broadband receiver used in this work is also sensitive to sferics from IC lightnings during thunderstorms (Rodger et al., 2006). Johnson and Inan (2000) reported that IC lightning associated with sferics generally do not propagate over distances larger than 500$800 \mathrm{~km}$. The modeling studies of thundercloud fields by Rycroft and Cho (1998), and observations of spider light- ning by Stanley (2000) accompanying sprites, suggest that IC discharges might play an important role in the generation processes of sprites. It has been suggested that ELF/VLF sferic clusters are indicative of sprite-producing discharges (Johnson and Inan, 2000; Ohkubo et al., 2005). A comparison of the spectrogram of the strong ELF-VLF sferic shown in Fig. 5 with those presented by Johnson and Inan (2000) and Ohkubo et al. (2005) shows that this sferic was even stronger in ELF components, even after traveling a distance of about $1100 \mathrm{~km}$, indicating a strong possibility of a TLE (sprite) associated with this event.

Early/slow events have previously been observed when the TRCGPs were in the dark (Haldoupis et al., 2004, 2006; Kumar et al., 2008), but not for daylight paths. The occurrence of early/slow events in the daytime is rare and has not been reported to date. A total of 10 early/slow events were observed when the TRGCPs were completely in the daylight. Six of these early/slow events occurred on NWC and NPM (three events simultaneously on each transmitter) on 7 November 2006, in the time interval 00:34-00:58 (hh:mm) UT due to three lightning events. All 6 early/slow events on 7 November occurred both in the amplitude and the phase, whereas the remaining 4 daytime early/slow events on other days occurred only on the amplitude. A record of daytime early/slow events observed on 7 November, simultaneously on the NWC and NPM signals, is shown in Figs. 6(a) and (b). The sudden change in phase marked by $\mathrm{X}$ in panel (a) is not an early VLF event, as phase did not recover after reaching its peak value. The amplitude onset duration of the perturbation event marked by the line with arrows is about $3 \mathrm{~s}$ and phase onset is about $0.9 \mathrm{~s}$. The recovery times of phase perturbation on the NWC and NPM signals are about $45 \mathrm{~s}$ and $32 \mathrm{~s}$, respectively, which are comparable with the nighttime events. This event appears to develop in two steps in the amplitude, marked by 1 and 2 in panel (b) with slow 
onset durations of about $1.2 \mathrm{~s}$ and $1.8 \mathrm{~s}$, respectively, indicating it to comprising two independent early/slow events due to two separate lightnings most likely happening at the same place, with a second event during the onset of the rst event. The recovery times of the amplitude perturbations on the NWC and NPM signals, measured with respect to the second step (marked as 2), are about $46 \mathrm{~s}$ and $33 \mathrm{~s}$, respectively. The recovery time of this event is larger, probably due to association with two stronger lightnings. The WWLLN did not detect the lightnings for the events presented in panels (a) and (b), and broadband data were not recorded in the daytime. Daytime early/slow events occurring simultaneously on the NWC and NPM signals provide evidence of a secondary ionization in the daytime $D$-region, produced by EMP elds of successive lightning discharges and/or horizontal components of in-cloud lightnings associated with CGs. The recovery of about $45 \mathrm{~s}$ of these events (Fig. 6) indicates that the electron density perturbations occurred at a higher altitude, where the electron density relaxation times are comparable with the night-time electron density relaxation times. The secondary ionization responsible for the slow onset will require much stronger EMP elds to produce the successive electron density perturbations in the daytime $D$-region, compared with the nighttime $D$-region, as the daytime $D$-region would absorb a part of the EMP radiation. However, the simulation and modeling studies on the interaction of lightning EMP in the nighttime $D$-region ionosphere, carried out by Rodger et al. (2001) and Marshall et al. (2008), if extended for daytime $D$ region ionospheric conditions, might con rm whether electron density perturbations associated with stronger EMPs eld could be possible.

\subsection{Unusually long recovery early/fast events}

Early/fast events with unusually long recovery times (5$20 \mathrm{~min}$ ) that are much longer than typical early/fast events were rst reported by Cotts and Inan (2007). In that study, the unusually long early/fast events were presented on a Low Frequency NAU transmitter $(40.75 \mathrm{kHz})$ received at Gander (GA), Newfoundland, and Boston, USA, and on some other mid- to low-latitude paths. Our data also shows early/fast events with unusually long recoveries that last up to 5-20 min or more. Such early/fast events are mainly observed on the NPM and NLK transmitters, but are rarely seen on other transmitters. These unusually long recovery perturbations are similar to those reported by Cotts and Inan (2007). Following the approach of Cotts and Inan (2007), the recovery times of these events were determined using amplitude perturbations within an error bound of $10 \%$ (i.e., recovery to $90 \%$ of the initial level) to allow for the presence of ionospheric uctuations occurring on timescales of a few minutes. Out of 245 early VLF events on NPM-Suva (seabased) seen in the three months of data, 17 (7\%) events were observed to show unusually long recoveries ( $\geq 5 \mathrm{~min}$ ). All such events were found to have strong amplitude perturbations of $\geq 1 \mathrm{~dB}$. Cotts and Inan (2007) found 5-7.5\% of total events on sea-based paths, and about $1.5 \%$ on land-based path, with recoveries larger $\geq 9 \mathrm{~min}$, indicating that the most frequent occurrence of unusually long recovery events occurred on sea-based paths. The paths selected by Cotts and Inan (2007) are such that some of the long recovery events could be due to WEP and caused by sustained precipitation. Figures 7(a)-(d) show examples of unusually long duration early/fast events observed when TRGCPs were in the dark. The recovery times calculated from amplitude perturbations are indicated in the panels. The phase builds with time therefore, in the case of long recovery events, the amplitude perturbation gives a better measure of the recovery times. The simultaneous occurrence of early/fast events both on NPM and NLK (panels 7(c) and 7(d)) indicates that the causative lightning was located within the NPM-Suva path (in the low-latitude belt), therefore, the perturbation event observed on NLK is certainly an early/fast event because WEP associated perturbations on a latitude path as that of NPM-Suva are unlikely to occur. The event shown in Fig. 7(c) is a step-like long recovery event in which the amplitude does not return to the pre-event level (Cotts and Inan, 2007). As seen from Figs. 7(c) and 7(d), the direction of the phase is opposite between the NPM-Suva and NLK-Suva paths. The relative position of electron density perturbations with respect to TRGCPs determines the nature of the phase and amplitude at any station. According to Dowden et al. (1992), the area between the transmitter and receiver in the vicinity of TRGCP can be divided into Fresnel zones (elliptical areas with different eccentricity ratios) having the transmitter and receiver as their focal points. The scattered waves from different Fresnel zones can have \pm amplitude and phase perturbations. For example, if the signals coming from two transmitters have their TRGCPs close to each other, one can register a positive phase while the other can have a negative phase. This is because the Lightning Induced Enhancement (LIE) could be in different Fresnel zones for different paths. The amplitude and phase of these events do not recover simultaneously, unlike typical early/fast events, and, in some cases, do not return to the initial level. Location of WWLLN-detected lightning discharges associated with the perturbation events shown in panels 7(a) and 7(b) (vertical lines with arrows) shows that these events were produced by narrow-angle scattering. No lightning discharges were recorded by WWLLN at the time of the perturbation events in the panels 7(c) and 7(d). This is, however, probably due to WWLLN's low detection ef ciency rather than the absence of lightning.

Unusually long recovery early/fast events seem to be associated with conductivity changes at the altitudes where relaxation times are longer than $5 \mathrm{~min}$. This may be possible at higher altitudes of about 80-90 km due to electronic conductivity perturbations, or at a lower altitude of about 50-60 km due to ionic conductivity perturbations (Cotts and Inan, 2007). The theoretical model reported by Marshall and Inan (2010) has shown that strong lightning EMPs can lead to ionization at elve-altitudes $(\sim 80-90 \mathrm{~km})$ which can yield measurable VLF perturbations. The large smoothlyvarying ionization can lead to early/fast events with long recovery times due to the long relaxation times of electrons at such altitudes. Based on a modeling study of EMP effects on the lower ionosphere Rodger et al. (2001) have shown that a two-fold increase in the ionization at $90-\mathrm{km}$ altitude would take about $30 \mathrm{~min}$ to return to $10 \%$ of the ambient value, indicating that such events could be associated with elves. However, elve-related perturbations observed during 

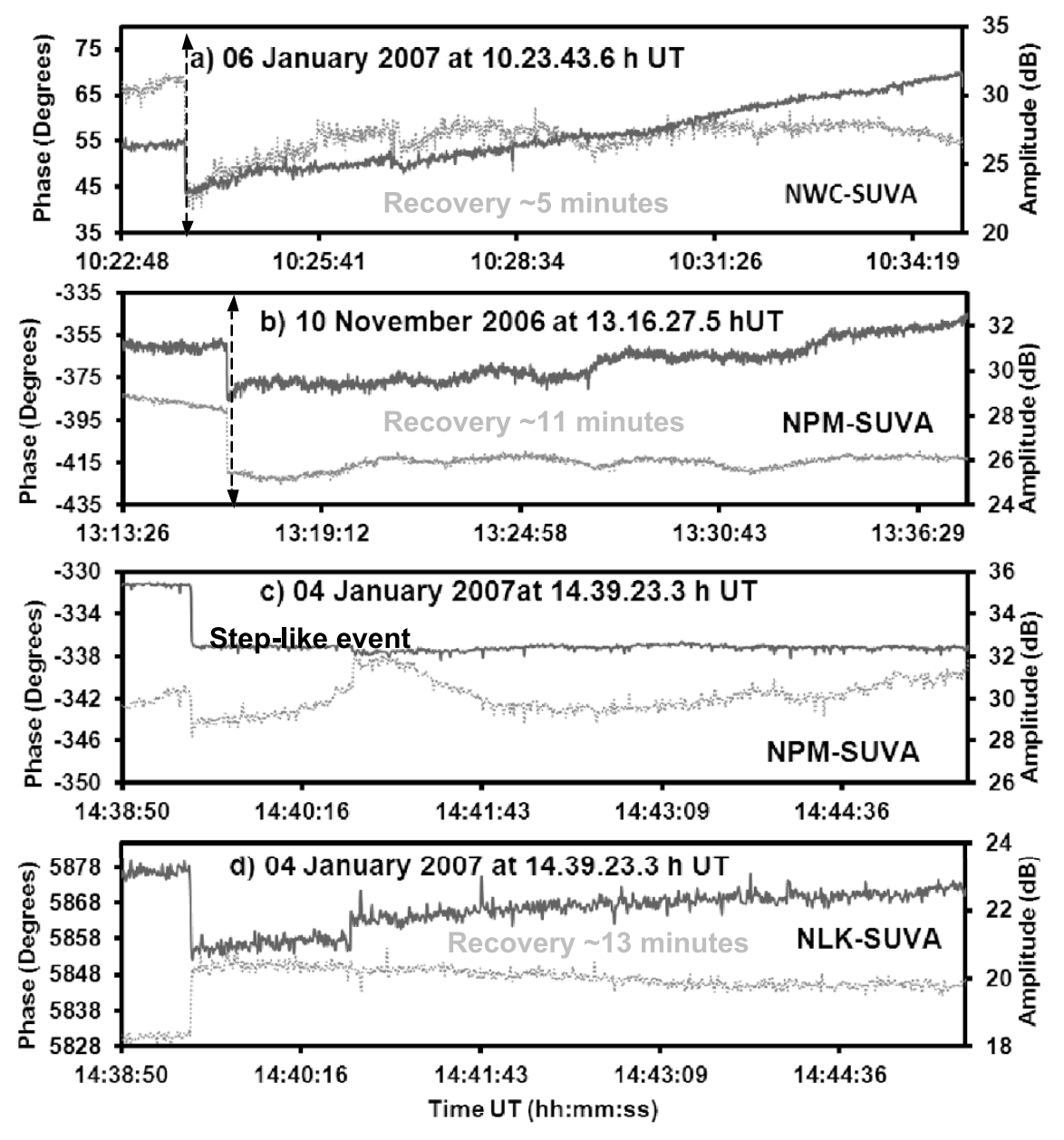

Fig. 7. (a)-(d): Typical examples of unusually long recovery early/fast events observed on NWC (a) NPM (b-c), and NLK (d) transmitters. The vertical dashed line in panels (a) and (b) indicates the time of lightning detected by WWLLN. Solid traces (blue color) and dotted traces (red color) represent amplitude and the phase, respectively. The event in paned (c) is step-like event with no clear recovery.

the EuroSprite 2003 had weaker amplitude perturbations of 0.15-0.4 dB with recoveries of 2-3 minutes (Mika et al., 2006). Cotts and Inan (2007) have suggested the possibility that the slow recovery of ionic conductivity perturbations at $65 \mathrm{~km}$ could occur in association with gigantic jets (GJs). All the unusually long duration early/fast events observed at Suva were found to have strong amplitude perturbations of $\geq 1 \mathrm{~dB}$ (those 4 early/fast events presented here in Fig. 7 have strong perturbations $>2 \mathrm{~dB}$ ) indicating that these events are most likely associated with strong ionic conductivity perturbations, possibly due to gigantic jets as suggested by Cotts and Inan (2007). From an analysis of TLEs observed by ISUAL, Chen et al. (2008) have shown a global rate of $3.23,0.50,0.39$, and 0.01 events per minute for elves, sprites, halos, and GJs, respectively. Thus, the fewer occurrences of unusually long recovery events are consistent with the lowest global occurrence $(0.01$ per minute) of GJs. No GJs were recorded by ISUAL along the NPM-Suva path within $200 \mathrm{~km}$ off the TRGCP during the period of VLF observations presented in this study. Lehtinen and Inan (2007) proposed a new chemistry model for the stratosphere/lower ionosphere, and attributed long recoveries $\left(\sim 10^{3}\right.$ to $\left.10^{4} \mathrm{~s}\right)$ of early/fast events to the persistent ionization generated by gigantic jet discharges at low altitude. The recent observations of a GJ-followed sprite by van der Velde et al. (2010), and associated strong early/fast VLF amplitude perturbations ( $>1 \mathrm{~dB}$ ) observed concurrently with a GJ, confirm the production of large electron density enhancements in the $D$-region of the ionosphere due to GJs. However, a part of the electron density enhancement was most likely due to the associated sprite. Large electron density perturbations at a higher altitude may produce strong perturbations but not the unusual long recovery as the relaxation time is less for a higher-order of electron density enhancements (Haldoupis et al., 2009). The initial faster recovery in some cases, as evident in Fig. 7(a) and (b), could be due to larger electron density enhancements with faster relaxation times in the $D$-region of the ionosphere, but the unusually long recovery times of events presented here is most likely associated with the persistent ionic conductivity changes in the lower $D$-region ionosphere associated with GJs, as suggested by Cotts and Inan (2007), or due to the complex events having both sprites and GJs. This is clearly an area for further experimental and theoretical research.

\section{Summary and Conclusions}

Early VLF events observed on signals from four VLF transmitters (NWC, NPM, VTX, NLK) using SoftPAL from November 2006 to January 2007, were analysed to study their occurrence and scattering characteristics, at a low lat- 
itude station Suva, Fiji, in the South Paci c Region. The period of November-January falls in the wet season with frequent lightnings and thunderstorms. Early VLF events are found to occur most frequently on transmission from NWC and least frequently on transmission from VTX. It is most likely that a combination of the transmitter power, frequency, stability of signals, occurrence of lightnings around the TRGCPs, and the TRGCP distances, determine the occurrence rate and nature of early VLF events. The main ndings of the present study are summarized as follows:

(1) Early VLF events coincident with WWLLN-detected lightnings, located within $500 \mathrm{~km}$ off the TRGCPs, show the possibility of VLF perturbations produced by wide-angle scattering. The analysis shows that about $73 \%$ (54 out of 74 ), and about $27 \%$ (20 out of 74 ), of early VLF events coincident with WWLLN lightnings were associated with narrow-angle and wideangle scatterings, respectively. This is also supported by the simultaneous occurrence of early VLF events on the NWC and NPM signals. However, this is a topic for continued research in view of the lower detection ef ciency of WWLLN.

(2) Daytime early/fast events are weak (0.2-0.5 dB) with only negative amplitude perturbations with shorter recovery times (10-40 s), indicating the occurrence of $D$-region electron density perturbations possibly associated with daytime TLEs (mainly sprites) producing ionization at a lower altitude where the electron density relaxation time is fast due to a comparatively higher electron collision frequency.

(3) Early/slow events occur on the signals mainly when their TRGCPs are in the dark. An example of an early/slow event associated with a very strong sferic with ELF components (even after a propagation distance of about $1100 \mathrm{~km}$ ), and a few others without an ELF component, is shown. The onset of this event indicates that TLEs (sprites) due to strong CG lightning triggered the onset of these events, and that EMPs associated with sferic clusters (IC discharges and/or due to in-cloud components of CG) contributed to the slow onset, which is consistent with earlier results on early/slow events.

(4) We have presented the rst evidence of daytime early/slow events, which occurred both on amplitude and phase. The recovery time ( $\sim 45 \mathrm{~s})$ of these events is comparable with nighttime early/fast and early/slow events. Such a recovery indicates the occurrence of sprites at a higher altitude, or daytime elves where relaxation times are larger, and the possibility of secondary ionization due to strong EMPs in the daytime. Such early/slow events are very rare.

(5) An initial study on unusually long recovery (5-20 min or more) early/fast events at our station, Suva, indicates that they mainly occur on NPM and NLK to Suva (sea-based) paths, when their TRGCPs are in darkness. Such events make up about $7 \%$ of total events on the NPM signal and have strong amplitude and phase perturbations. There is the possibility that these events are associated with strong ionic conductivity perturba- tions in the lower part of the $D$-region possibly associated with gigantic jets, as suggested by Cotts and Inan (2007), or due to complex events having both sprites and GJs. However, this is clearly an area for further experimental and theoretical research.

Acknowledgments. The authors are thankful to the Faculty Research Committee, The University of the South Paci c (USP), for providing support through a research grant and wish to thank WWLLN for providing the lightning location data. One author (Sushil Kumar) thanks the Department of Physics, Otago University, New Zealand, for providing the facilities under Ratu Sir Kamisese Mara Visiting Fellowship in which he could complete this work. We are grateful to Craig J. Rodger of Otago University for helpful discussions.

\section{References}

Armstrong, W. C., Recent advances from studies of the Trimpi effect, Antarctic J., USA, 18, 281-283, 1983.

Chen, A. B. et al., Global distributions and occurrence rates of transient luminous events, J. Geophys. Res., 113, A08306, doi:10.1029/2008JA013101, 2008.

Christian, H. J., R. J. Blakeslee, D. J. Boccippio, W. L. Boeck, D. E. Buechler, S. J. Driscoll, K. T. Goodman, J. M. Hall, W. J. Koshak, D. M. Mach, and M. F. Stewart, Global frequency and distribution of lightnings as observed from space by the Optical transient Detector, $J$. Geophys. Res., 108, doi:10.1029/2002JD002347, 2003.

Cotts, B. R. T. and U. S. Inan, VLF observation of long ionospheric recovery events, Geophys. Res. Lett., 34, L14809, doi:10.1029/ 2007GL030094, 2007

Dowden, R. L., Comment on 'VLF signatures of ionospheric disturbances associated with sprites', Geophys. Res. Lett., 23, 3421-3422, 1996.

Dowden, R. L. and C. D. D. Adams, SoftPAL, Proceedings of the 3rd VERSIM Workshop, Tihany, Hungary, 15-20 Sept. 2008.

Dowden, R. L. and C. J. Rodger, Decay of a vertical plasma column A model to explain VLF sprites, Geophys. Res. Lett., 24, 2765-2768, 1997.

Dowden, R. L., C. D. D. Adams, and P. D. Cotton, Use of VLF transmissions in the location and mapping of lightning-induced ionisation enhancements (LIEs), J. Atmos. Terr. Phys., 54, 1355-1373, 1992.

Dowden, R. L., C. D. D. Adams, J. B. Brundell, and P. E. Dowden, Rapid onset, rapid decay, (RORD), phase and amplitude perturbations of VLF subionospheric transmissions, J. Atmos. Terr. Phys., 56, 1513-1527, 1994

Dowden, R. L., J. B. Brundell, W. A. Lyons, and T. E. Nelson, Detection and location of red sprites by VLF scattering of subionospheric transmissions, Geophys. Res. Lett., 23, 1737-1740, 1996.

Dowden, R. L., J. B. Brundell, and C. J. Rodger, Temporal evolution of very strong Trimpis observed at Darwin, Australia, Geophys. Res. Lett., 24, 2419-2422, doi:10.1029/97GL02357, 1997.

Dowden, R. L., R. H. Holzworth, C. J. Rodger, J. Lichtenberger, N. R. Thomson, A. R. Jacobson, E. Lay, J. B. Brundell, T. J. Lyons, S. O'Keefe, Z. Kawasaki, C. Price, V. Prior, P. Ortega, J. Weinman, Y. Mikhailov, R. Woodman, X. Qie, G. Burns, A. Collier, O Pinto Jr., R. Diaz, C. Adamo, E. R. Williams, S. Kumar, G. B. Raga, J. M. Rosado, E. E. Avila, M. A. Clilverd, T. Ulich, P. Gorham, T. J. G. Shanahan, T. Osipowicz, G. Cook, and Y. Zhao, World-wide lightning location using VLF propagation in the earth-ionosphere waveguide, IEEE Ant. Propag. Mag., 50(5), 40-60, 2008.

Farges, T., E. Blanc, A. Le Pichon, T. Neubert, and T. H. Allin, Identi cation of infrasound produced by sprites during the Sprite2003 campaign, Geophys. Res. Lett., 32, L01813, doi:10.1029/2004GL021212, 2005.

Fernsler, R. F. and H. L. Rowland, Models of lightning-produced sprites and elves, J. Geophys. Res., 101, 29653-29662, 1996.

Füllekrug, M., C. Price, Y. Yair, and E. R. Williams, Intense oceanic lightning, Ann. Geophys., 20, 133-137, 2002.

Haldoupis, C., T. Neubert, U. S. Inan, A. Mika, T. H. Allen, and R. A Marshall, Subionospheric early VLF signal perturbation observations in one-to-one association with sprites, J. Geophys. Res., 109, A110303, doi:10. 1029/2004JA010651, 2004.

Haldoupis, C., R. J. Steiner, A. Mika, S. Shalimov, R. A. Marshall, U. S. Inan, T. Bosinger, and T. Neubert, Early/slow event: A new category of 
VLF perturbations observed in relation with sprites, J. Geophys. Res., 111, doi:10.1029/2006JA011960, 2006.

Haldoupis, C., A. C. Mika, and S. Shalimov, Modeling the relaxation of early VLF perturbations associated with transient luminous events, $J$. Geophys. Res., 114, A00E04, doi:10.1029/2009JA014313, 2009.

Haldoupis, C., N. Amvrosiadi, B. R. T. Cotts, O. A. van der Velde, O. Chanrion, and T. Neubert, More evidence for a one-to-one correlation between Sprites and Early VLF perturbations, J. Geophys. Res., 115, A07304, doi:10.1029/2009JA015165, 2010.

Hardman, S. F., C. J. Rodger, R. L. Dowden, and J. B. Brundell, Measurements of the VLF scattering pattern of the structured plasma of red sprites, IEEE Trans. Ant. Propag., 40, 29-38, 1998.

Inan, U. S., D. C. Shafer, W. P. Yip, and R. E. Orville, Subionospheric VLF signatures of nighttime D region perturbations in the vicinity of lightning discharges, J. Geophys. Res., 93(A10), 11,455-11,472, 1988.

Inan, U. S., T. F. Bell, V. P. Pasko, D. D. Sentman, E. M. Wescott, and W. A. Lyons, VLF signatures of ionospheric disturbance associated with sprites, J. Geophys. Res., 22, 3461-3464, 1995.

Inan, U. S., A. Slingeland, V. P. Pasko, and J. V. Rodriguez, VLF and LF signatures of mesospheric/lower ionospheric response to lightning discharges, J. Geophys. Res., 101, 5219-5238, 1996 a.

Inan, U. S., T. F. Bell, and V. P. Pasko, Reply, Geophys. Res. Lett., 23, 3423-3424, 1996b.

Inan, U. S., S. A. Cummer, and R. A. Marshall, A survey of ELF/VLF research of lightning-ionosphere interactions and causative discharges, J. Geophys. Res., 115, A00E36, doi:10.1029/2009JA014775, 2010.

Johnson, M. P. and U. S. Inan, Sferic clusters associated with early/fast VLF events, Geophys. Res. Lett., 27, 1391-1394, 2000.

Johnson, M. P., U. S. Inan, S. J. Lev-Tov, and T. F. Bell, Scattering patterns of lightning-induced ionospheric disturbances associated with early/fast VLF events, Geophys. Res. Lett., 26, 23663-23644, 1999.

Kumar, S., S. K. Dixit, and A. K. Gwal, Propagation of tweek atmospherics in the earth-ionosphere waveguide, IL Nuovo Cimento, 17, 275-281, 1994.

Kumar, S., A. Kishore, and V. Ramachandran, Higher harmonic tweek sferics observed at low latitude: estimation of VLF re ection heights and tweek propagation distance, Ann. Geophys., 26, 1451-1459, 2007.

Kumar, S., A. Kumar, and C. J. Rodger, Subionospheric early VLF perturbations observed at Suva: VLF detection of red sprites in the day, $J$. Geophys. Res., 113, A03311, doi:10.1029/2007JA012734, 2008.

Lehtinen, N. G. and U. S. Inan, Possible persistent ionization caused by giant blue jets, Geophys. Res. Lett., 34, L08804, doi:10.1029/2006GL02905, 2007.

Marshall, R. A. and U. S. Inan, Two-dimensional frequency domain modeling of lightning EMP-induced perturbations to VLF transmitter signals, J. Geophys. Res., 115, A00E29, doi:10.1029/2009JA014761, 2010.

Marshall, R. A., U. S. Inan, and W. A. Lyons, On the association of early/fast very low frequency perturbations with sprites and rare examples of VLF backscatter, J. Geophys. Res., 111, D19108, doi:10.1029/2006JD007219, 2006.

Marshall, R. A., U. S. Inan, and T. W. Chevalier, Early VLF perturbations caused by lightning EPM-driven dissociative attachment, Geophys. Res. Lett., 35, L21807, doi:10.1029/2008GL035358, 2008.

Mika, A. C., C. Haldoupis, R. A. Marshall, T. Neubert, and U. S. Inan, Subionospheric VLF signatures and their association with sprites observed during EuroSprite2003, J. Atmos. Sol.-Terr. Phys., 67, 1580-
$1597,2005$.

Mika, A. C., C. Haldoupis, T. Neubert, T. S. Su, R. R. Hsu, T. S. R. J. Steiner, and R. A. Marshall, Early VLF perturbations observed in association with elves, Ann. Geophys., 24, 2179-2189, 2006.

Mika, A. and C. Haldoupis, VLF studies during TLE occurrence in Europe: A summary of new ndings, Space Sci.Rev., doi:10.1007/s 11214-0089382-8, 2008

Molchanov, O. A., A. V. Shvets, and M. Hayakawa, Analysis of lightning-induced ionization from VLF Trimpi events, J. Geophys. Res., 103(A10), 23,443-23,458, 1998.

NaitAmor, S., M. A. AlAbdoadaim, M. B. Cohen, B. R. T. Cotts, S. Soula, O. Chanrion, T. Neubert, and T. Abdelatif, VLF observations of ionospheric disturbances in association with TLEs from the EuroSprite2007 campaign, J. Geophys. Res., 115, A00E47, doi:10.1029/2009JA015026, 2007.

Ohkubo, A., H. Fukunishi, Y. Takahashi, and T. Adachi, VLF/ELF sferics evidence for in-cloud discharge activity producing sprites, Geophys. Res. Lett., 32, Lo4812, doi:10.1029/2004GL021943, 2005.

Pasko, V. P., U. S. Inan, T. F. Bell, and S. C. Reising, Mechanism of ELF radiation from sprites, Geophys. Res. Lett., 25, 3493-3496, 1998.

Rodger, C. J., Subionospheric VLF perturbations associated with lightning discharges, J. Atmos. Sol.-Terr. Phys., 65, 591-606, doi:10.1016/S13646826(02)00325-5, 2003.

Rodger, C. J. and D. Nunn, VLF scattering from red sprites: Application of numerical modeling, Radio Sci., 34(4), 923-932, 1999.

Rodger, C. J., M. Cho, M. A. Clilverd, and M. J. Rycroft, Lower ionospheric modi cation by lightning EMP: Simulation of the nighttime ionosphere over the United States, Geophys. Res. Lett., 28, 199-202, 2001.

Rodger, C. J., S. W. Werner, J. B. Brundell, N. R. Thomson, E. H. Lay, R. H. Holzworth, and R. L. Dowden, Detection ef ciency of the VLF World-Wide Lightning Location Network (WWLLN): Initial case study, Ann. Geophys., 24, 3197-3214, 2006.

Rycroft, M. J. and M. Cho, Modelling electric and magnetic elds due to thunderclouds and lightnings from cloud-tops to the ionosphere, $J$. Atmos. Sol.-Terr. Phys., 60, 889-893, 1998.

Sampath, H. T., U. S. Inan, and M. P. Johnson, Recovery signatures and occurrence properties of lightning-associated subionospheric VLF perturbations, J. Geophys. Res., 105, 183-191, 2000.

Stanley, M. A., Sprites and their parent discharges, PhD thesis, New Mexico Institute of Mining and technology, 2000.

Stanley, M. A., M. Brrok, P. Krehbiel, and S. A. Cummer, Detection of daytime sprites via a unique sprite ELF signature, Geophys. Res. Lett., 27, 871-874, 2000.

van der Velde, O. A., J. Bór, J. Li, S. A. Cummer, E. Arnone, F Zanotti, M. Füllekrug, C. Haldoupis, S. NaitAmor, and T. Farges, Multi instrumental observations of a positive gigantic jet produced by a winter thunderstorm in Europe, J. Geophys. Res., 115, D24301, doi:10.1029/2010JD014442, 2010

Voss, H. D., W. Walt, W. L. Imhof, J. Mobilia, and U. S. Inan, Satellite observations of lightning-induced electron precipitation, J. Geophys. Res., 103, 11725-11744, 1998.

S. Kumar (e-mail: sushil.kumar@usp.ac.fj) and A. Kumar 